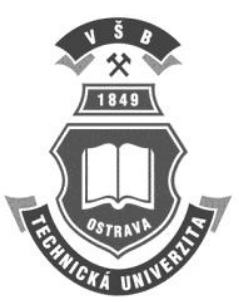

\title{
The influence of advertising on the purchase of pharmaceutical products
}

\author{
Jana VALEČKOVÁ, VŠB-TU Ostrava ${ }^{\mathrm{i}}$
}

\begin{abstract}
The size of the pharmaceutical market and pharmaceutical sales is increasing constantly. The market is flooded with new drugs and preparations. There is an increasing amount of advertising (e.g. television and print) for these medicaments. This paper analyses the relationship between (1) advertisement awareness and the purchase of medicaments and (2) noticing advertising leaflets in a pharmacy and the purchase of medicaments. Five groups of drugs are monitored, namely vitamins and minerals, immunity support medicines, painkillers, pharmaceutical cosmetics and medicines to support the nervous system. Analysis is carried out using logistic regression methods to determine the odds ratio of purchase and purchase probability. The coefficients are estimated using the maximum likelihood method. The contribution involves listing those pharmaceutical products whose purchase is influenced by advertising. We found relationships between purchase and advertisement awareness (print and television) for vitamins and minerals, painkillers and pharmaceutical cosmetics, and relationships between purchase and the perception of leaflets for vitamins and minerals, pharmaceutical cosmetics and immunity support medicines.
\end{abstract}

\section{Keywords}

Advertising, logistic regression, marketing research, odds ratio, over-the-counter products, pharmaceutical market, purchase probability

JEL Classification: M31, M37

\footnotetext{
${ }^{\mathrm{i}}$ Department of Marketing and Business, Faculty of Economics, VŠB-Technical University of Ostrava, Sokolská 33, 70121 Ostrava, Czech Republic.

jana.valeckova@vsb.cz

The paper has been supported by the SGS research project SP2011/38 of VSB-TU Ostrava.
}

\section{Introduction}

Currently, there is a large pharmaceutical market boom and expansion of pharmaceutical products. Healts IMS predicts that the pharmaceutical market will grow by $5-8 \%$ annually to 2014 and that the sale of pharmaceutical products will grow by around $4 \%$ to $6 \%$ annually (Kroček, 2010). The main areas of interest for pharmaceutical manufacturers are product quality, customer satisfaction and loyalty. Pharmaceutical companies try to identify their customers, define the target group and manage marketing activities, and gain customer loyalty (Szeinbach et al., 1997).
When the market is growing, marketing activities in connection with the development of new products or upgrade of existing ones grow in importance, while new marketing communication concepts (advertising) and new distribution channels are also created. These activities are linked to the analysis of customers and monitoring of the decision-making processes for overthe-counter drugs, supplements and other pharmaceutical products. It is necessary to identify the factors that influence the purchase decision such as personal characteristics, customer experience, attitude to products, health and the role of the influencer (doctor, pharmacist and family), need for purchase, availability 
of medicaments, medicaments advertising and prices of medicines.

Advertising expenditure is increasing every year. The direct-to-customer spending activity of US pharmaceutical manufacturers increased from 266 million dollars in 1994 to 2,467 million dollars in 2000. In $2000,36.4 \%$ was spent on print and other media and $63.6 \%$ on television advertising (Vogel et al., 2003). Manufacturers often show two types of advertising: (1) help-seeking advertisements (disease description but not treatment description) and (2) reminder advertisements (product name, without indication) (Vogel et al., 2003).

This paper identifies the relationship between the following variables: (1) the purchase of preparation (drugs) and awareness of relevant advertising and (2) the purchase of preparation (drugs) and noticing advertising leaflets in a pharmacy. It assesses whether there is a relationship between purchasing and advertising and quantifies the strength of this relationship. The dependent variable (purchase of drugs in both cases) is binary, and the analysis is carried out using logistic regression. The paper analyses five categories of drugs, namely vitamins and minerals, immunity support medicines, painkillers, pharmaceutical cosmetics and medicines to support the nervous system.

Section 2 describes the theoretical background of purchasing decisions and the impact of advertising on purchase, while Section 3 presents the theoretical background of logistic regression analysis. Section 4 describes the methodology of data collection and analysis. The results are summarised in Section 5.

\section{Purchasing decisions and impact of advertising}

Customer behaviour reflects the totality of their decisions regarding goods, services, activities and ideas, namely the acquisition, consumption and disposal of goods or services (Hoyer and MacInnis, 2007). Kotler (2003) states that customer behaviour is influenced by cultural, social and personal factors. Cultural factors are presented as the largest and broadest group and they include ethnicity, religion, racial group and social class. Social factors comprise family, reference groups, social role and position in society. Personal factors include age, occupation and lifestyle.

There are two approaches to the analysis of customers: quantitative and qualitative. Qualitative analysis may be performed by the black box model, which is based on stimulus and response. Advertising can be one of the stimuli. A marketer looks for the reasons why a customer responded. Another qualitative analysis is based on the decision-making process, which includes (1) recognising the problem, (2) searching for information, (3) evaluating alternatives, (4) purchase decision and (5) behaviour after purchase (Spáčil, 2003).

Customer behaviour is an ongoing process. This process does not end with purchase and payment. It involves the handling of products, repeat purchases and satisfied or unsatisfied behaviour (Solomon et al., 2006). Customer behaviour involves many different actors. Each of them has a different role. Each role may be performed by one person or one person can perform many roles. The purchaser and user of a product may not be the same person. Other roles include informant, decider and influencer (Solomon et al., 2006).

Customer behaviour comprises five elements (Figure 1). Each of these elements influences marketing strategies and tactics. In models of customer behaviour, many questions describe behaviour accurately, such as what a customer buys and when and where a customer buys it. The actors in a decision-making process have many roles: information gatherer, influencer, decider, purchaser and user. The decisionmaking process takes place at a certain time.

Advertising can play an important role in a decision-making process, especially informing and influencing. Advertising informs about new and existing medicaments, and an advertisement may have different forms such as television and radio advertising, advertising on the Internet, in pharmacies or in magazines. This is valid for the medicaments freely available.

In 1999, pharmaceutical companies spent 1.8 billion dollars on direct-to-consumer advertising compared with less than 300 million dollars in 1994 (Woloshin et al., 2001). US research on prescription drugs has shown that customers are increasingly exposed to direct-to-consumer advertisements. The results show that doctors are increasingly confronted with patients who ask questions or who make suggestions based on these advertisements (Woloshin et al., 2001).

\section{Theoretical background of logistic regression analysis}

Logistic regression analysis is a mathematical modelling approach to describe the relationships between several independent variables and a dichotomous dependent variable. The dependent variable can take two values: zero (e.g., dissatisfaction, ignorance of brand, product is not purchased) or 1 (e.g., satisfaction, brand awareness, purchase of product). The model can thus predict purchase probability (Kleinbaum and Klein, 2010). 

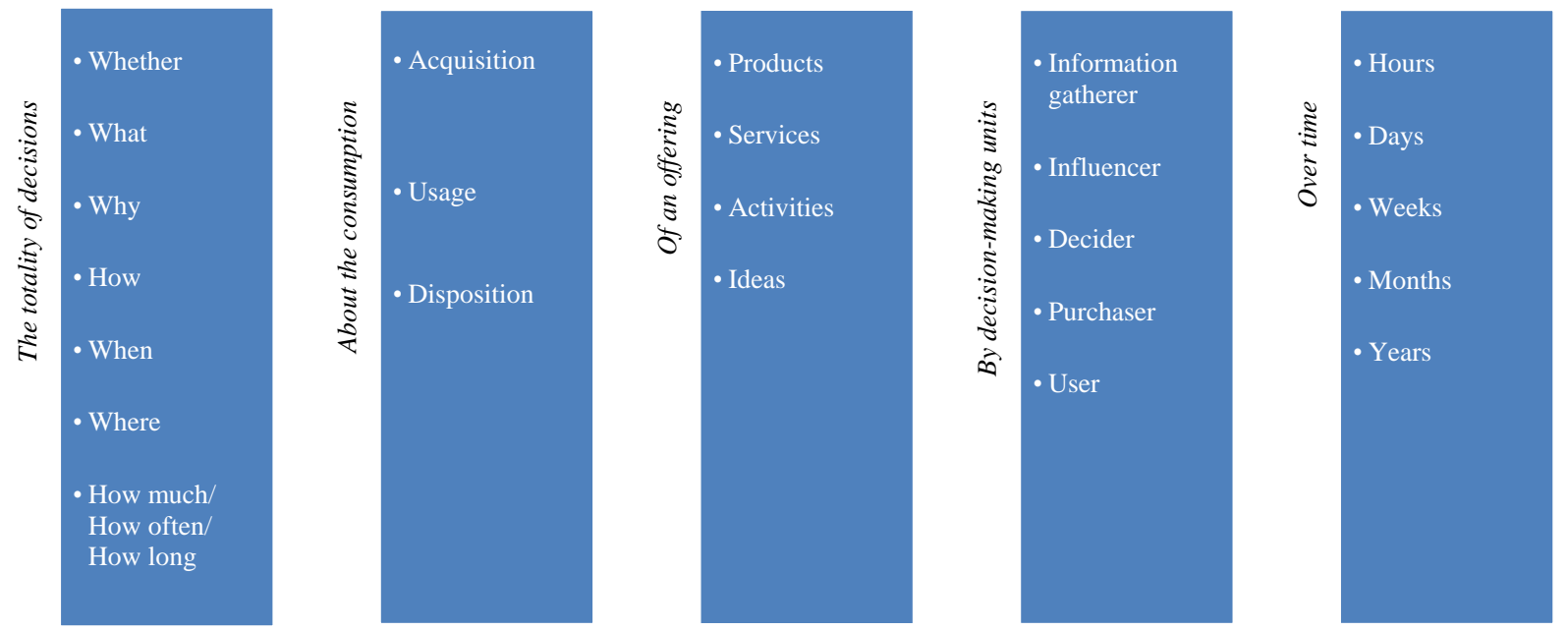

Figure 1 Five elements that influence customer behaviour Source: Hoyer and Macinnis (2007)

\subsection{Formulation of the model}

Consider a binary variable $Y_{i}$ characterising the positive and negative response to the $i$-th respondent for $i=1, \ldots, N$, where $N$ is the number of respondents. Each respondent is characterised by the vector $\mathbf{x}_{i}=\left(1, x_{1 i}, x_{2 i}, \ldots ., x_{K i}\right) \quad$ containing $\quad K \quad$ elements (Pecáková, 2007).

The likelihood of a positive response of the $i$-th respondent $P_{i}=P\left(Y_{i}=1\right)$ on the basis of its characteristic vector $\mathbf{x}_{i}$ can be expressed as function $F\left(\boldsymbol{\beta}, \mathbf{x}_{i}\right)$, which is increasing and has a domain of definition $(-\infty,+\infty)$ and a range $(0,1)$, so it is accepted that the $F(-\infty)=0 \quad$ a $\quad F(+\infty)=1$ likelihood function of a response can be written as

$$
P_{i}=F\left(\boldsymbol{\beta}, \mathbf{x}_{i}\right),
$$

where $\boldsymbol{\beta}$ is vector of parameters $\left(\beta_{0}, \beta_{1}, \ldots, \beta_{K}\right)$.

These properties are the cumulative distribution function of the logistic distribution in the shape

$$
P_{i}=P\left(Y_{i}=1\right)=F\left(\boldsymbol{\beta}, \mathbf{x}_{i}\right)=\frac{e^{\beta^{\prime} \mathbf{x}_{i}}}{1+e^{\beta^{\prime} \mathbf{x}_{i}}},
$$

which is a function of the probability of the answer. The probability of a negative response is $1-P_{i}$. (Hosmer and Lemeshow, 2000).

The definition of the percentage probability of positive and negative responses (odds) is in the form (Pecáková, 2007)

$$
\frac{\pi}{1-\pi}=\frac{P\left(Y_{i}=1\right)}{P\left(Y_{i}=0\right)}=e^{\beta^{\prime} \mathbf{x}_{i}} .
$$

The odds ratio for the dichotomous variable $\left(x_{j}\right.$ takes values 0 or 1) is (Hilbe, 2009)

$$
\text { OR }(1,0)=\frac{\pi\left(x_{j}=1\right) /\left[1-\pi\left(x_{j}=1\right)\right]}{\pi\left(x_{j}=0\right) /\left[1-\pi\left(x_{j}=0\right)\right]}=\exp \left(\beta_{j}\right) \text {. }
$$

\subsection{An estimate of model parameters}

Unknown parameter $\boldsymbol{\beta}$ is estimated using the method of maximum likelihood. This method consists of finding a likelihood function, which is maximised after that. The likelihood of a positive answer from the $i$-th respondent, which is characterised by the vector $\mathbf{x}_{i}$, is then

$$
P\left(Y_{i}=1 \mid \mathbf{x}_{i}\right)=\pi\left(\mathbf{x}_{i}\right),
$$

and the likelihood of a negative response is $1-\pi\left(\mathrm{x}_{i}\right)$.

The combined probability of positive and negative responses can be written then as (Hosmer and Lemeshow, 2000)

$$
P\left(Y_{i} \mid \mathbf{x}_{i}\right)=\pi\left(\mathbf{x}_{i}\right)^{Y_{i}}\left[1-\pi\left(\mathbf{x}_{i}\right)\right]^{\left(1-Y_{i}\right)} .
$$

If each observation is independent, then the likelihood function is defined as the result of equation (6) for all respondents. Parameters using the maximum likelihood method are obtained by maximising the logarithm of the likelihood function in the form (Hosmer and Lemeshow, 2000)

$$
\begin{aligned}
L(\boldsymbol{\beta}) & =\ln l(\boldsymbol{\beta})= \\
& =\sum_{i=1}^{N} Y_{i} \cdot \ln \left(\pi\left(\mathbf{x}_{i}\right)\right)+\left(1-Y_{i}\right) \cdot \ln \left(1-\pi\left(\mathbf{x}_{i}\right)\right) .
\end{aligned}
$$




\section{Analysis of the influence of advertising on purchasing}

The following subsections describe the methodology of data collection through primary research and the analysis of various categories of pharmaceutical products.

\subsection{Data collection methodology}

The data used in the model were collected through marketing research. Data were obtained from written questionnaires in the Moravia region in December 2010 using the snowball method, a non-representative sampling technique. A group of respondents approached other respondents. The condition of place of residence (Moravia region) and age (more than 18 years old) were fulfilled for all respondents. The size of the sample was 289 respondents. The distribution of advertisement awareness (yes or no) can be seen in Table 1 in the appendix. This is categorised according to groups of medicaments. Table 1 shows the number of respondents who purchased (1) vitamins and minerals, (2) immunity support medicines, (3) painkillers, (4) pharmaceutical cosmetics or (5) medicines to support the nervous system. The analysis was performed using the Stata statistical program.

The distribution of respondents' answers to the leaflets in pharmacies can be seen in Table 2 in the appendix. The aim of this question was to ascertain whether respondents observe the advertising leaflets and brochures. There were three options: respondents ignore the leaflets; respondents observe the leaflets, but are not interested in them; and respondents observe the leaflets and are interested in them. These customer groups are termed ignorers, uninterested customers and interested customers hereafter. This table is also classified according to groups of medicaments and grouped according to the same five purchase categories.

In the following section, five groups of drugs are analysed to assess whether the relationship between advertisement awareness (print and television) and the purchase of drugs is significant. We define the chance of purchasing when a customer notices the advertisement (or not). We determine the degree of the probability of purchase when a customer notice an advertisement and not. Although the main points of the analysis are the estimation of the logistic regression models, further information obtained from the primary research (in December 2010) is also listed in the analysis. Such information deals with the reasons for buying medicaments (purchase as prevention and purchase after the outbreak of disease).

Testing was carried out at the 5\% significance level. The dependent variable was the purchase of medicaments $(1=$ yes; $0=$ no). The first independent variable was advertisement awareness $(1=$ yes; $0=$ no) and the second independent variable was interest in leaflets and brochures of pharmaceutical products $(1=$ ignore; $2=$ observe, not interested in; $3=$ observe, interested in). Confirmation or rejection of the significance of the model was determined by the Pvalue, which can be obtained from the estimated regression model or through the use of MS Office Excel functions $\operatorname{FDIST}\left(\mathrm{F}^{\mathrm{vyp}}, d f_{\mathrm{ESS}}, d f_{\mathrm{RSS}}\right)$, (Zmeškal, 2004).

Subsections 3.2 to 3.6 present the estimated models for the categories of pharmaceutical products. In each category, there are two estimations: the relationship among (1) advertisement awareness and the purchase of medicaments and (2) noticing the advertising leaflets in the pharmacy and the purchase of medicaments. There are thus 10 estimated models.

\subsection{Vitamins and minerals}

Within the category vitamins and minerals two aspects has been analysed, advertisement awareness and leaflets.

\section{Advertisement awareness}

The results of the first analysis are presented in Figure 2. Customers who are not exposed to advertisements are the reference group. Rvitamny (in Figure 2) includes customers who noticed advertising for vitamins and minerals. A low $\mathrm{R}^{2}$ value in the logistic regression is the norm, which presents a problem when reporting their values to an audience accustomed to seeing linear regression values. It may be helpful as a statistical tool to evaluate a competing model (Hosmer and Lemeshow, 2000). In the logistic model, it is not appropriate to use a classic $\mathrm{R}^{2}$, so we used pseudo $\mathrm{R}^{2}$ instead. There are several ways to calculate the pseudo $\mathrm{R}^{2}$ (Hilbe, 2009).

We find that the relationship between the purchase and awareness of advertisements for vitamins and minerals is significant at the $5 \%$ level. The purchase of vitamins and minerals is dependent on advertisements (print or television). Thus, advertising is an important factor on purchase.

The result of the analysis shows an odds ratio of 2.151. This is presented in Figure 3. The odds ratio is the ratio of the odds of purchasing when customers are exposed and not exposed to advertising. Here, the odds ratio is greater than 1, so the odds of purchase are greater when customers are aware of the advertising. The odds of purchasing vitamins and minerals when customers are exposed (not exposed) to advertising are 2.868 (1.334). The probability of purchase is 0.742 in the first case and 0.571 in the second case. These results are based on Formula 2 in Chapter 3.1. 


\begin{tabular}{|c|c|c|c|c|c|c|c|}
\hline \multicolumn{4}{|c|}{ Logistic regression } & \multicolumn{2}{|c|}{$\begin{array}{l}\text { Number of obs } \\
\text { LR chi2 (1) } \\
\text { Prob > chi2 } \\
\text { Pseudo R2 }\end{array}$} & $\begin{array}{l}= \\
= \\
= \\
=\end{array}$ & $\begin{array}{r}28 \\
7.84 \\
0.0051 \\
0.0220\end{array}$ \\
\hline vitamny & coef. & Std. Err. & z & $P>|z|$ & {$[95 \%$} & onf. & Interval] \\
\hline $\begin{array}{r}\text { rvitamny } \\
\text { _cons }\end{array}$ & $\begin{array}{l}.7659065 \\
.2876821\end{array}$ & .272136 & $\begin{array}{l}2.81 \\
1.30\end{array}$ & $\begin{array}{l}0.005 \\
0.192\end{array}$ & $\begin{array}{r}.2325 \\
-.1444\end{array}$ & & $\begin{array}{l}1.299283 \\
.7198135\end{array}$ \\
\hline
\end{tabular}

Figure 2 Estimation of logistic regression for vitamins and minerals (advertisement awareness)

\begin{tabular}{|c|c|c|c|c|c|c|c|}
\hline \multicolumn{4}{|c|}{ Logistic regression } & \multicolumn{2}{|c|}{$\begin{array}{l}\text { Number of obs } \\
\text { LR chi2 (1) } \\
\text { Prob > chi2 } \\
\text { Pseudo R2 }\end{array}$} & $\begin{array}{l}= \\
= \\
= \\
=\end{array}$ & $\begin{array}{r}289 \\
7.84 \\
0.0051 \\
0.0220\end{array}$ \\
\hline vitamny & Odds Ratio & Std. Err. & $z$ & $P>|z|$ & {$[95 \%$} & onf. & Interval] \\
\hline rvitamny & 2.150943 & .5853491 & 2.81 & 0.005 & 1.261 & & 3.666668 \\
\hline
\end{tabular}

Figure 3 Odds ratio for vitamins and minerals (advertisement awareness)

The equation of the estimated model in this case is as follows:

$$
P_{i}=P\left(Y_{i}=1\right)=\frac{e^{\left(0.2876821+0.7659065 \cdot x_{i}\right)}}{1+e^{\left(0.2876821+0.7659065 \cdot x_{i}\right)}},
$$

where $P$ is the probability of purchasing vitamins and minerals, $i=1, \ldots, N$, where $N$ is the number of respondents. If the customer is exposed to advertising, then $x_{i}$ is 1 and if 0 otherwise.

\section{Advertising leaflets in pharmacy}

Figure 4 presents the estimation of the logistic regression model for vitamins and minerals. Ignorers are the reference group. Iletak_2 (in Figure 4) means uninterested customers and Iletak_3 means interested customers. In this case, it is apparent that the independent variables are statistically significant. The purchase of vitamins and minerals is dependent on the attitude to leaflets in the pharmacy. The P-values of independent variables are less than 0.05 .

The odds of purchasing vitamins and minerals by uninterested customers are 3.237, the odds of purchasing vitamins and minerals by interested customers are 15.393, and the odds of the purchases by ignorers are 1.079. The odds are greater when customers are interested in the leaflets. This is confirmed by the purchase probabilities. The purchase probability for interested customers is 0.939 . The purchase probability for uninterested customers is 0.764 . The purchase probability for ignorers is 0.519. If interest in the leaflet increases, then the purchase probability of vitamin and minerals increases too. The odds ratio is given by Formula 4 in Chapter 3.1 and the purchase probability is based on Formula 2 listed in Chapter 3.1. The odds ratio equals 3.25 . This means that the odds of the purchase are 3.25 times larger when customers observe the leaflets (listed in Figure 5).
The significant influence of advertising on the purchase of vitamins and minerals is proven by the analysis. If customers notice the advertising messages in print or on television, the purchase probability of this medication category is significantly increased. The purchase probability is greater by 0.17 . The relationship between the advertising leaflets in the pharmacy and purchase of medicaments is also demonstrated. If customers are interested in the leaflets strongly, then the purchase probability is 0.42 larger than when they are not.

The results of the primary research also show that $75 \%$ of users buy vitamins and minerals before the disease occurs. Because most customers buy these medicaments beforehand, they have time to get information from many sources at the beginning of the decision-making process. The information comes from internal sources (own experience) or external sources. They can obtain information about medicaments from own experience, family, friends, doctors, pharmacists or discussion forums on the Internet. Marketing communication (specifically advertising) is also an important source of information.

Customers look for more information in addition to the above listed sources before the outbreak of the disease (probably in winter months). Advertisements in print or on television are an important source of such information. The influence of advertising on the purchase of vitamins and minerals is shown above. The research results do not show the intensity level of information resources on a customer's decision. There is identified a relationship between advertising message and purchase.

The equation of the estimated model in this case is as follows:

$$
P_{i}=P\left(Y_{i}=1\right)=\frac{e^{\left(0.074108+1.97932 \cdot x_{1 i}+2.666732 \cdot x_{2 i}\right)}}{1+e^{\left(0.074108+1.97932 \cdot x_{1 i}+2.666732 x \cdot x_{2 i}\right)}},
$$




\begin{tabular}{|c|c|c|c|c|c|c|c|}
\hline \multicolumn{4}{|c|}{$\begin{array}{l}\text { Logistic regression } \\
\text { Log likelihood }=-163.28607\end{array}$} & \multicolumn{2}{|c|}{$\begin{array}{l}\text { Number of obs } \\
\text { LR chi2(2) } \\
\text { Prob > Chi2 } \\
\text { Pseudo R2 }\end{array}$} & $\begin{array}{l}= \\
= \\
= \\
=\end{array}$ & $\begin{array}{r}289 \\
30.32 \\
0.0000 \\
0.0850\end{array}$ \\
\hline vitaminy & coef. & std. Err. & $\mathbf{z}$ & $P>|z|$ & {$[95 \%$} & Conf. & Interva1] \\
\hline $\begin{array}{r}\text { Iletak_2 } \\
\text { Iletak_3 } \\
\text { _cons }\end{array}$ & $\begin{array}{r}1.097932 \\
2.666732 \\
.074108\end{array}$ & $\begin{array}{l}.2729632 \\
.7545502 \\
.1925822\end{array}$ & $\begin{array}{l}4.02 \\
3.53 \\
0.38\end{array}$ & $\begin{array}{l}0.000 \\
0.000 \\
0.700\end{array}$ & $\begin{array}{r}.5629 \\
i .187 \\
-.3033\end{array}$ & $\begin{array}{l}9338 \\
7841 \\
3462\end{array}$ & $\begin{array}{r}1.63293 \\
4.145623 \\
.4515622\end{array}$ \\
\hline
\end{tabular}

Figure 4 Estimation of the logistic regression for vitamins and minerals (leaflets in pharmacy)

Logistic regression
Log 1ikelihood = -163.45154

Figure 5 Odds ratios for vitamins and minerals (leaflets in pharmacy)

where $P$ is the probability of the purchase of vitamins and minerals. If the customer ignores the leaflets, then $x_{1 i}=0$ and $x_{2 i}=0$. If the customer observes the leaflets but is not interested in them, then $x_{1 i}=1$ and $x_{2 i}=0$. If the customer observes the leaflets and is interested in them, then $x_{1 i}=0$ and $x_{2 i}=1$.

The best estimated model is related to the category vitamins and minerals. This is indicated by Pseudo $\mathrm{R}^{2}$, which is low. This is helpful as a statistic for evaluating a competing model. The best quality estimation is the model for vitamins and minerals. The actual results are illustrated in the figures above.

\subsection{Immunity support medicines}

Also within the second category, the advertisement awareness as well as the leaflets is analysed.

\section{Advertisement awareness}

Figure 6 shows the estimation of the logistic regression model for this group of medicaments. Customers who are not exposed to advertising are the reference group. Rimunita (in Figure 6) means customers who have noticed the advertising for immunity support medicines.

It is necessary to determine whether the relationship between the two variables is statistically significant. The P-value for the coefficient is 0.069 . Testing is carried out at the 5\% significance level. The purchase of immunity support medicines is not dependent on advertisement awareness (print or television). The conclusion is that advertisement awareness is not an important factor in the purchase of immunity support medicines.

\section{Advertising leaflets in pharmacy}

The relation between purchase and interest in leaflets is tested in the following part. Ignorers are the refer- ence group. Iletak_2 (in Figure 7) means uninterested customers and Iletak_3 means interested customers. Dependence is identified based on statistical testing carried out at the 5\% significance level. Thus, the coefficients are statistically significant. The P-value for the independent variable is less than 0.05 (Figure 7). There is statistical significance between the purchase of immunity support medicines and interest in leaflets in a pharmacy.

The odds of purchasing immunity support medicines for interested customers are 2.3, the odds of purchasing immunity support medicines for uninterested customers are 1.278 and the odds of the purchases for ignorers are 0.686 . The odds are greater when customers are interested in the leaflets. The purchase probability for interested customers is 0.697. The purchase probability for uninterested customers is 0.561 . The purchase probability for ignorers is 0.407 . If interest in the leaflets increases, then the purchase probability of immunity support medicines increases, too. The purchase probability is based on Formula 2 listed in Chapter 3.1.

The odds ratio is 1.839 . This means that the odds of purchase are 1.839 times larger when customers observe the leaflets (listed in Figure 8). The odds ratio in this product category is less than in the previous category (vitamins and minerals). The odds ratio is given by Formula 4 in Chapter 3.1.

The purchase probability of immunity support medicines increases when interest in print advertising in pharmacies increases, too. This claim is statistically proven. Immunity support medicines aim to prevent. Thus, customers would probably use (or buy) this group of drugs before the outbreak of disease. The research showed that $65 \%$ of users buy these medicaments before the outbreak of disease. Customers make reserves of these medicaments as with vitamins and minerals. Immunity support medicines and vitamins 


\begin{tabular}{|c|c|c|c|c|c|c|c|}
\hline \multicolumn{4}{|c|}{$\begin{array}{l}\text { Logistic regression } \\
\text { Log 1ikelihood }=-198.44598\end{array}$} & \multicolumn{2}{|c|}{$\begin{array}{l}\text { Number of obs } \\
\text { LR chi2 (1) } \\
\text { Prob > chi2 } \\
\text { Pseudo R2 }\end{array}$} & $\begin{array}{l}= \\
= \\
= \\
=\end{array}$ & \multirow{2}{*}{$\begin{array}{r}289 \\
3.33 \\
0.0681 \\
0.0083 \\
\text { Interva1] }\end{array}$} \\
\hline imunita & coef. & Std. Err. & $z$ & $P>|z|$ & {$[95 \%$} & Conf. & \\
\hline $\begin{array}{r}\text { rimunita } \\
\text { cons }\end{array}$ & $\begin{array}{r}.4308191 \\
-.1391128\end{array}$ & $\begin{array}{r}.2368325 \\
.16707\end{array}$ & $\begin{array}{r}1.82 \\
-0.83\end{array}$ & $\begin{array}{l}0.069 \\
0.405\end{array}$ & $\begin{array}{l}-.03 \\
-.46\end{array}$ & & $\begin{array}{l}.8950021 \\
.1883384\end{array}$ \\
\hline
\end{tabular}

Figure 6 Estimation of logistic regression for immunity support medicines (advertisement awareness)

Logistic regression
Log like1ihood $=-194.72832$

Figure 7 Estimation of logistic regression for immunity support medicines (leaflets in pharmacy)

Logistic regression
Log likelihood $=-194.72993$

Figure 8 Odds ratio for immunity support medicines (leaflets in pharmacy)

and minerals can be identical in some cases. The reasons for consumption may be the same. These categories may show similar results but the effect of the advertising message on the purchase of immunity support medicines has not been proven. The effect of information leaflets on the purchase of immunity support medicines is proven. This effect is significantly higher in the case of vitamins and minerals.

Immunity support medicines are seasonal purchases. Greater demand and a greater concentration of interest are probably higher at the end of the year and the beginning of a new one (i.e. winter). Demand and interest are probably lower in summer. A customer's interest in information will increase during this period. This is a good time for print advertising in pharmacies because influence has been proven.

The equation of the estimated model in this case is as follows:

$$
P_{i}=P\left(Y_{i}=1\right)=\frac{e^{\left(-0.3746934+0.6191468 \cdot x_{1 i}+1.207603 \cdot x_{2 i}\right)}}{1+e^{\left(-0.3746934+0.6191468 \cdot x_{1 i}+1.207603 x^{\prime \prime} \cdot x_{2 i}\right)}}
$$

where $P$ is the probability of the purchase of immunity support medicines, similar to Formula 9.

\subsection{Painkillers}

The same approach as above is used to analyse also the painkillers category.

\section{Advertisement awareness}

Figure 9 shows the estimation of the logistic regression model for painkillers. Customers who are not exposed to advertising are the reference group. Rbolest (in Figure 9) means customers who have noticed the advertisements for painkillers. The coefficients are estimated using the maximum likelihood method. The coefficients and constants are statistically significant; the P-value for coefficients is $0.041 \quad(0.041<0.05)$. Therefore, advertisement awareness is an important factor in the purchase of painkillers.

The odds ratios are listed in Figure 10. The odds of purchase when customers are aware of the advertisement are 4.568 and the odds of purchase when they are not aware are given by a constant value $\exp (0.8994836)=2.458$. The purchase probability in the first case is 0.82 and that in the second case is 0.711. The results are based on the formulas in Chapter 3 (Formulas 2 and 4).

The equation of the estimated model in this case is as follows:

$$
P_{i}=P\left(Y_{i}=1\right)=\frac{e^{\left(0.8994836+0.6194972 \cdot x_{i}\right)}}{1+e^{\left(0.8994836+0.6194972 \cdot x_{i}\right)}},
$$

where $P$ is the probability of the purchase of painkillers, as in Formula 8. 


\begin{tabular}{|c|c|c|c|c|c|c|c|}
\hline \multicolumn{4}{|c|}{ Logistic regression } & \multicolumn{2}{|c|}{$\begin{array}{l}\text { Number of obs } \\
\text { LR chi2 (1) } \\
\text { Prob > chi2 } \\
\text { Pseudo R2 }\end{array}$} & $\begin{array}{l}= \\
= \\
= \\
=\end{array}$ & $\begin{array}{r}289 \\
4.08 \\
0.0433 \\
0.0137\end{array}$ \\
\hline bolest & coef. & Std. Err. & z & $P>|z|$ & {$[95 \%$} & ionf. & Interval] \\
\hline $\begin{array}{r}\text { rbolest } \\
\text { _cons }\end{array}$ & $\begin{array}{l}.6194972 \\
.8994836\end{array}$ & $\begin{array}{r}.3025888 \\
.242107\end{array}$ & $\begin{array}{l}2.05 \\
3.72\end{array}$ & $\begin{array}{l}0.041 \\
0.000\end{array}$ & $\begin{array}{l}.0264 \\
.42496\end{array}$ & & $\begin{array}{r}1.21256 \\
1.374005\end{array}$ \\
\hline
\end{tabular}

Figure 9 Estimation of logistic regression for painkillers (advertisement awareness)

\begin{tabular}{|c|c|c|c|c|c|c|c|}
\hline \multicolumn{4}{|c|}{ Logistic regression } & \multicolumn{2}{|c|}{$\begin{array}{l}\text { Number of obs } \\
\text { LR chi2(1) } \\
\text { Prob > chi2 } \\
\text { Pseudo R2 }\end{array}$} & $\begin{array}{l}= \\
= \\
= \\
=\end{array}$ & $\begin{array}{r}289 \\
4.08 \\
0.0433 \\
0.0137\end{array}$ \\
\hline bolest & odds Ratio & std. Err. & $z$ & $P>|z|$ & {$[95 \%$} & Conf. & Interva1] \\
\hline rbolest & 1.857994 & .5622081 & 2.05 & 0.041 & 1.026 & 6786 & 3.362082 \\
\hline
\end{tabular}

Figure 10 Odds ratio for painkillers (advertisement awareness)

\begin{tabular}{|c|c|c|c|c|c|c|c|}
\hline \multicolumn{4}{|c|}{ Logistic regression } & \multicolumn{2}{|c|}{$\begin{array}{l}\text { Number of obs } \\
\text { LR chi2(2) } \\
\text { Prob > chi2 } \\
\text { Pseudo R2 }\end{array}$} & $\begin{array}{l}= \\
= \\
= \\
=\end{array}$ & $\begin{array}{r}289 \\
3.46 \\
0.1775 \\
0.0116\end{array}$ \\
\hline bolest & coef. & std. Err. & $\mathbf{z}$ & $P>|z|$ & {$[95 \%$} & Conf. & Interva1] \\
\hline $\begin{array}{r}\text { Iletak_2 } \\
\text {-Iletak_3 } \\
\text { _cons }\end{array}$ & $\begin{array}{l}.3620055 \\
.9311793 \\
1.049822\end{array}$ & $\begin{array}{r}.3018284 \\
.576799 \\
.2195775\end{array}$ & $\begin{array}{l}1.20 \\
1.61 \\
4.78\end{array}$ & $\begin{array}{l}0.230 \\
0.106 \\
0.000\end{array}$ & $\begin{array}{r}-.2295 \\
-.1993 \\
.6194\end{array}$ & $\begin{array}{l}5673 \\
3259 \\
4581\end{array}$ & $\begin{array}{l}.9535784 \\
2.061685 \\
1.480186\end{array}$ \\
\hline
\end{tabular}

Figure 11 Estimation of logistic regression for painkillers (leaflets in pharmacy)

\begin{tabular}{|c|c|c|c|c|c|c|c|}
\hline \multicolumn{3}{|c|}{ Logistic regression } & & \multicolumn{2}{|c|}{$\begin{array}{l}\text { Number of obs } \\
\text { LR chi2(1) } \\
\text { Prob > chi2 } \\
\text { Pseudo R2 }\end{array}$} & $\begin{array}{l}= \\
= \\
= \\
=\end{array}$ & $\begin{array}{r}289 \\
14.70 \\
0.0001 \\
0.0367\end{array}$ \\
\hline kosmetika & coef. & Std. Err. & z & $P>|z|$ & {$[95 \%$} & Conf. & Interva1] \\
\hline $\begin{array}{r}\text { rkosmetika } \\
\text { _cons }\end{array}$ & $\begin{array}{r}.9620279 \\
-.3126834\end{array}$ & $\begin{array}{l}.2557622 \\
.1480456\end{array}$ & $\begin{array}{r}3.76 \\
-2.11\end{array}$ & $\begin{array}{l}0.000 \\
0.035\end{array}$ & $\begin{array}{r}.4607 \\
-.6028\end{array}$ & $\begin{array}{l}433 \\
473\end{array}$ & $\begin{array}{r}1.463313 \\
-.0225194\end{array}$ \\
\hline
\end{tabular}

Figure 12 Estimation of logistic regression for pharmaceutical cosmetics (advertisement awareness)

\section{Advertising leaflets in pharmacy}

Ignorers are the reference group. Iletak_2 (in Figure 11) means uninterested customers and Iletak_3 means interested customers. The P-values for both coefficients are greater than 0.05 at the $5 \%$ significance level. The estimation results are presented in Figure 11. The information brochures and leaflets located in pharmacies are not decisive for the purchase of this category of pharmaceutical products.

Painkillers are purchased by consumers if they or their friends and family suffer painful problems (occasionally or regularly). Consumers buy drugs on a regular basis if they know their problems. These medicaments can be purchased for random pain or in the case of serious health complications. In the second case, medicaments are usually prescribed by a physician.

Painkillers solve problems that have developed or will develop in the near future. In total, $44 \%$ of users buy painkillers before the disease occurs as prevention. The influence of advertising on the purchase of painkillers has been shown. Advertising is likely to affect all groups of users who suffer from minor health problems and who know that these problems will occur.

\subsection{Pharmaceutical cosmetics}

The pharmaceutical cosmetics is another group. There are analyzes of advertisement awareness and advertising leaflets in pharmacy.

\section{Advertisement awareness}

Figure 12 shows the estimation of the logistic regression model for pharmaceutical cosmetics. Customers who are not exposed to advertising are the reference group. Rkosmetika (in Figure 12) means customers who noticed the advertising for pharmaceutical cosmetics. The P-value is less than 0.05, implying that advertisement awareness, in print or on television, is 
an important factor for purchase. The purchase of pharmaceutical cosmetics is thus dependent on seeing advertisements (print or television). Other factors are not analysed. Pharmaceutical cosmetics are slightly different in relation to other medicaments.

Some customers buy these products because they provide a sense of higher values than the cosmetics sold in chemist chains. Health is not the only reason for the purchase of pharmaceutical cosmetics. The need to test quality cosmetics may be a reason for purchase. Information about the existence of this product is often obtained from advertising.

The odds ratio for the purchase of pharmaceutical cosmetics is presented in Figure 13. The odds ratio is 2.617. This number means that the purchase of pharmaceutical cosmetics is 2.617 times greater when customers are aware of the advertisement than when they are not. The odds of purchase when customers are aware of the advertisement are 1.914 and the odds of purchasing when customers are not aware are 0.731 . The purchase probability in the first case is 0.657 and that in the second case is 0.422 . The odds ratio is given by Formula 4 in Chapter 3.1 and the purchase probability is based on Formula 2 listed in Chapter 3.1.

The equation of the estimated model in this case is as follows:

$$
P_{i}=P\left(Y_{i}=1\right)=\frac{e^{\left(-0.3126834+0.9620279 \cdot x_{i}\right)}}{1+e^{\left(-0.3126834+0.9620279 \cdot x_{i}\right)}},
$$

where $P$ is the probability of the purchase of pharmaceutical cosmetics, as in Formula 8.

\section{Advertising leaflets in pharmacy}

The estimation of the logistic regression model for the cosmetics from pharmacies is listed in Figure 14. Ignorers are the reference group. Iletak_2 (in Figure 14) means uninterested customers and Iletak_3 means interested customers. The values of coefficients and constants follows. It is necessary to determine whether there is a relationship between the purchase of pharmaceutical cosmetics and interest in leaflets in pharmacies. This relationship is confirmed by the P-value, which for the first coefficient is statistically significant (uninterested customers). The P-value of the second coefficient is not statistically significant (interested customers). It is thus necessary to combine these categories to make a new estimation for the logistic regression.

The reference variable is ignorers. Ignorers and interested customers in the questionnaire are merged. The results of the new estimation are presented in Figure 15. The P-value is less than 0.05 , and thus the coefficient is statistically significant. Figure 16 shows the odds ratio (Formula 4, Chapter 3.1) of the pur- chase of this category of products. It equals 1.672. This product category is recoded. In the first group, there are ignorers and interested customers, and in the second group are uninterested customers. The odds of purchases in the first group are 0.667, and the purchase probability is 0.44 . The odds of purchases in the second group are 1.135 , and the purchase probability is 0.568 . The purchase probability is based on Formula 2 listed in Chapter 3.1.

Purchase is influenced by print and television advertising, which has been statistically proven. A significant influence is confirmed but the first step (one of need) in the buying process can be different. Different customers have different needs. The elimination of skin problems can be the first reason for purchasing pharmaceutical cosmetics; these problems are eliminated after their occurrence. A total of $46 \%$ of users buy pharmaceutical cosmetics after disease occurs. If customers buy pharmaceutical cosmetics preventively, then advertising on television, in magazines or in pharmacies may play an important role. Advertising will be a great source of information in the buying process. This is verified by own testing.

The range of pharmaceutical cosmetics and intensity of advertising campaigns have been growing recently. There are products such as shampoos, face and body creams, shower gels, decorative cosmetics and sun cream in pharmacies. Pharmaceutical cosmetics can replace products from drugstore chains. Users are mostly women. The look of quality cosmetics with medicinal effects can be a reason to buy these products at pharmacies rather than in drugstore chains. Information is often communicated in advertising campaigns. The impact of these campaigns in this group of pharmaceutical products is due to the characteristics of the products listed above. This fact has been confirmed by statistical testing. Thus, the significant influence of advertising on purchase is confirmed.

The equation of the estimated model in this case is as follows:

$$
P_{i}=P\left(Y_{i}=1\right)=\frac{e^{\left(-0.2423135+0.5142472 \cdot x_{i}\right)}}{1+e^{\left(-0.2423135+0.5142472 \cdot x_{i}\right)}},
$$

where $P$ is the probability of the purchase of pharmaceutical cosmetics. If a customer ignores the leaflets or a customer observes them intensively, then $x_{i}=0$.

The reference category (ignorers) was merged with the third group (customers that observe leaflets intensively) in order to estimate the model. The statistical significance of coefficients was demonstrated after this merger. If the customer observes the leaflets but is not interested in them, then $x_{i}=1$. 


\begin{tabular}{|c|c|c|c|c|c|c|c|}
\hline \multicolumn{4}{|c|}{ Logistic regression } & \multicolumn{2}{|c|}{$\begin{array}{l}\text { Number of obs } \\
\text { LR chi2(1) } \\
\text { Prob }>\text { chi2 } \\
\text { Pseudo R2 }\end{array}$} & $\begin{array}{l}= \\
= \\
= \\
=\end{array}$ & $\begin{array}{r}289 \\
14.70 \\
0.0001 \\
0.0367\end{array}$ \\
\hline kosmetika & odds Ratio & Std. Err. & $\mathbf{z}$ & $P>|z|$ & {$[95 \%$} & onf. & Interva1] \\
\hline rkosmetika & 2.616998 & .6693291 & 3.76 & 0.000 & 1.585 & & 4.320247 \\
\hline
\end{tabular}

Figure 13 Odds ratio for pharmaceutical cosmetics (advertisement awareness)

Logistic regression
Log 1ikelihood =

Figure 14 Estimate of logistic regression for pharmaceutical cosmetics (leaflets in pharmacy)

\begin{tabular}{|c|c|c|c|c|c|c|c|}
\hline \multicolumn{4}{|c|}{ Logistic regression } & \multicolumn{2}{|c|}{$\begin{array}{l}\text { Number of obs } \\
\text { LR chi2(1) } \\
\text { Prob > chi2 } \\
\text { Pseudo R2 }\end{array}$} & $\begin{array}{l}= \\
= \\
= \\
=\end{array}$ & $\begin{array}{r}289 \\
4.73 \\
0.0296 \\
0.0118\end{array}$ \\
\hline kosmetika & Coef. & Std. Err. & $\mathbf{z}$ & $P>|z|$ & {$[95 \%$} & Conf. & Interva1] \\
\hline $\begin{array}{r}\text { Iletakn_2 } \\
\text { _cons }\end{array}$ & $\begin{array}{r}.5142472 \\
-.2423135\end{array}$ & $\begin{array}{l}.2373121 \\
.1696681\end{array}$ & $\begin{array}{r}2.17 \\
-1.43\end{array}$ & $\begin{array}{l}0.030 \\
0.153\end{array}$ & $\begin{array}{r}.0491 \\
-.5748\end{array}$ & $\begin{array}{l}1241 \\
8568\end{array}$ & $\begin{array}{l}.9793703 \\
.0902299\end{array}$ \\
\hline
\end{tabular}

Figure 15 Estimation of logistic regression for pharmaceutical cosmetics, recalculated (leaflets in pharmacy)

$\begin{array}{lllr}\text { Logistic regression } & \text { Number of obs } & & 289 \\ & \text { LR chi2(1) } & = & 4.73 \\ \text { Log 1ikelihood }=-197.93672 & \text { Prob }>\text { Chi2 } & = & 0.0296 \\ & \text { Pseudo R2 } & = & 0.0118\end{array}$

\begin{tabular}{r|rccccr}
\hline kosmetika & odds Ratio & std. Err. & z & P>|z| & [95\% Conf. Interva1] \\
\hline letakn & 1.672379 & .3968758 & 2.17 & 0.030 & 1.050351 & 2.662779 \\
\hline
\end{tabular}

Figure 16 Odds ratio for pharmaceutical cosmetics (leaflets in pharmacy)

Logistic regression
Log 1ike1ihood = -137.32311

Figure 17 Estimation of logistic regression for the medicines to support the nervous system (advertisement awareness)

\subsection{Medicines to support the nervous system}

The medicines to support the nervous system are the last category of drugs analyzed in the paper.

\section{Advertisement awareness}

According to the results in Figure 17, the coefficient is not statistically significant. Customers who are not exposed to advertising are the reference group. Rnervy (in Figure 17) means customers who noticed the advertising for medicines to support the nervous system.
The $\mathrm{P}$-value is 0.371 . The purchase of medicines to support the nervous system is not dependent on advertisement awareness (in print or on television). The purchase of these medicaments depends on other factors such as a consumer's health or attitude to medicaments.

\section{Advertising leaflets in pharmacy}

Figure 18 presents the results. Ignorers are the reference group. Iletak_2 (in Figure 18) means uninterested customers and Iletak_3 means interested customers. 


\begin{tabular}{|c|c|c|c|c|c|c|c|}
\hline \multicolumn{4}{|c|}{ Logistic regression } & \multicolumn{2}{|c|}{$\begin{array}{l}\text { Number of obs } \\
\text { LR chi2(2) } \\
\text { Prob > chi2 } \\
\text { Pseudo R2 }\end{array}$} & $\begin{array}{l}= \\
= \\
= \\
=\end{array}$ & $\begin{array}{r}289 \\
3.70 \\
0.1570 \\
0.0134\end{array}$ \\
\hline nervy & coef. & std. Err. & z & $P>|z|$ & {$[95 \%$} & Conf. & Interva1] \\
\hline $\begin{array}{r}\text { Iletak_2 } \\
\text { _Iletak_3 } \\
\text { _cons }\end{array}$ & $\begin{array}{r}.2492462 \\
.9162907 \\
-1.7492\end{array}$ & $\begin{array}{l}.3444867 \\
.4656692 \\
.2708682\end{array}$ & $\begin{array}{r}0.72 \\
1.97 \\
-6.46\end{array}$ & $\begin{array}{l}0.469 \\
0.049 \\
0.000\end{array}$ & $\begin{array}{r}-.4259 \\
-2035 \\
-2.280\end{array}$ & $\begin{array}{l}353 \\
958 \\
092\end{array}$ & $\begin{array}{r}.9244276 \\
i .828986 \\
-1.218308\end{array}$ \\
\hline
\end{tabular}

Figure 18 Estimation of logistic regression for the medicines to support the nervous (leaflets in pharmacy)

The purchase of medicines to support the nervous system is not dependent on customers' observations of leaflets in pharmacies. The P-value for the first coefficient is 0.469 and that for the second independent variable equals 0.049 . The second value is on the limit because the estimation is carried out at the 5\% significance level. The odds ratio and probability are not detected. This category includes products that are designed to eliminate insomnia and anxiety states and includes antidepressants or medications to stop smoking.

The influence of advertising on the purchase of this group was demonstrated in the analysis. In this case, there are important other sources of information because it is a different group of drugs. These products are used for psychological problems. The foregoing products (vitamins and minerals, painkillers, cosmetics, immunity support medicines) are intended for physical problems, e.g. pain and illness prevention.

These four categories show that advertising (advertisement awareness or advertising leaflets or both) influences purchase. The influence of advertisement awareness on the purchase of medicines for the nervous system support is not statistically confirmed. The test confirms the claim above that it is a special group of products. Purchase is influenced by other factors.

\section{Conclusion}

This paper analysed purchases in the pharmaceutical market, namely the influence of advertising on the purchase of five groups of pharmaceutical products: (1) vitamins and minerals, (2) immunity support medicines, (3) painkillers, (4) pharmaceutical cosmetics and (5) medicines to support the nervous system. The analysis was performed using the logistic regression approach because the dependent variable was binary. The estimate of the coefficient was performed using the maximum likelihood method in this regression model.

We found relationships between purchase and advertisement awareness (print and television) for vitamins and minerals, painkillers and pharmaceutical cosmetics, and relationships between purchase and the perception of leaflets for vitamins and minerals, pharmaceutical cosmetics and immunity support medicines. The influence of advertising was not found in the case of medicines to support the nervous system. Ten models were estimated. The best quality estimation was the model for vitamins and minerals.

Customers are influenced by numerous other factors than just advertising. These factors influence the process of making decisions and purchases. Only the impact of advertising was analysed in this paper. These factors will be monitored and analysed in further research. The next phase of the research will concentrate on the analysis of a customer. Customers can be segmented according to demographic, geographic, psychological and behavioural factors.

\section{Literature}

HILBE, J.M. (2009). Logistic Regression Models. Boca Raton: CRC Press.

HOSMER, D.W., LEMESHOW, S. (2000). Applied Logistic Regression. New York: Wiley. http://dx.doi.org/10.1002/0471722146

HOYER, W.D., MACINNIS, D.J. (2007). Consumer Behavior. Boston: Houghton Mifflin.

KLEINBAUM, D.G., KLEIN, M. (2010). Logistic Regression. A Self-Learning Text. New York: Springer.

KOTLER, P. (2003). Marketing management. Praha: Grada.

KROČEK, L.H. (2010). IMS předpovídá růst globálního farmaceutického trhu 5-8 \% ročně do roku 2014. Pharm Business Magazine 6: 2.

PECÁKOVÁ, I. (2007). Logistická regrese s vicekategoriální vysvětlovanou proměnou. Acta Oeconomica Pragensia 15: 86-96.

SOLOMON, M., BAMOSSY, G., ASKEGAARD, S., HOGG, M.K. (2006). Consumer Behavior. A European Perspective. New Jersey: Prentice-Hall.

SPÁČIL, V. (2003). Marketingové řizení: sylaby a prípadové studie. Ostrava: Repronis.

SZEINBACH, S.L., BARNES, J.H., GARNER, D.D. (1997). Use of pharmaceutical manufacturers valueadded services to build customer loyalty. Journal of Business Research 40(3): 229-236. 
http://dx.doi.org/10.1016/S0148-2963(96)00239-1

VOGEL, R.J., RAMACHANDRAN, S., ZACHRY, W.M. (2003). A 3-stage model for assessing the probable economic effects of eirect-to consumer advertising of pharmaceuticals. Clinical Therapeutics 25(1): 309-329. http://dx.doi.org/10.1016/S0149$\underline{2918(03) 90043-9}$
WOLOSHIN, S., SCHWARTZ, L.M., TREMMEL, J., WELCH, H.G. (2001). Direct-to-consumer advertisements for prescription drugs: what are Americans being sold? The Lancet 358(9288): 1141-1146. http://dx.doi.org/10.1016/S0140-6736(01)06254-7

ZMEŠKAL, Z. (2004). Finanční modely. Praha: Ekopress.

\section{Appendix}

Table 1 Distribution of purchase and advertisement awareness by the groups of medicaments

\begin{tabular}{|c|c|c|c|c|c|}
\hline \multirow{2}{*}{\multicolumn{3}{|c|}{ Groups of observed medicaments }} & \multicolumn{2}{|c|}{ Advertisement awareness } & \multirow{3}{*}{$\begin{array}{c}\text { Total } \\
200\end{array}$} \\
\hline & & & Yes & No & \\
\hline \multirow{3}{*}{ I. Vitamins and minerals } & \multirow{2}{*}{ Purchase } & Yes & $152(76 \%)$ & $48(24 \%)$ & \\
\hline & & No & $53(59.6 \%)$ & $36(40.4 \%)$ & 89 \\
\hline & \multicolumn{2}{|c|}{ Total } & $205(70.9 \%)$ & $84(29.1 \%)$ & 289 \\
\hline \multirow{3}{*}{ II. Medicines for immune support } & \multirow{2}{*}{ Purchase } & Yes & $83(55.4 \%)$ & $67(44.6 \%)$ & 150 \\
\hline & & No & $62(44.6 \%)$ & $77(55.4 \%)$ & 139 \\
\hline & \multicolumn{2}{|c|}{ Total } & $145(50.2 \%)$ & $144(49.8 \%)$ & 289 \\
\hline \multirow{3}{*}{ III. Painkillers } & \multirow{2}{*}{ Purchase } & Yes & $169(74.1 \%)$ & $59(25.9 \%)$ & 228 \\
\hline & & No & $37(60.7 \%)$ & $24(39.3 \%)$ & 61 \\
\hline & \multicolumn{2}{|c|}{ Total } & $206(71.3 \%)$ & $83(28.7 \%)$ & 289 \\
\hline \multirow{3}{*}{ IV. Pharmaceutical cosmetics } & \multirow{2}{*}{ Purchase } & Yes & $67(45.9 \%)$ & $79(54.1 \%)$ & 146 \\
\hline & & No & $35(24.5 \%)$ & $108(75.5 \%)$ & 143 \\
\hline & \multicolumn{2}{|c|}{ Total } & $102(35.3 \%)$ & $187(64.7 \%)$ & 289 \\
\hline \multirow{3}{*}{$\begin{array}{l}\text { V. Medicines to support the nervous } \\
\text { system }\end{array}$} & \multirow{2}{*}{ Purchase } & Yes & $11(20.8 \%)$ & $42(79.2 \%)$ & 53 \\
\hline & & No & $37(15.7 \%)$ & $199(84.3 \%)$ & 236 \\
\hline & \multicolumn{2}{|c|}{ Total } & $48(16.6 \%)$ & $241(83.4 \%)$ & 289 \\
\hline
\end{tabular}


Table 2 Distribution of purchase and interest leaflets by the groups of medicaments

\begin{tabular}{|c|c|c|c|c|c|c|}
\hline \multirow{2}{*}{\multicolumn{3}{|c|}{ Groups of observed medicaments }} & \multicolumn{3}{|c|}{ Advertising leaflets } & \multirow{3}{*}{$\begin{array}{r}\text { Total } \\
200\end{array}$} \\
\hline & & & \multirow{2}{*}{$\begin{array}{c}\text { Ignore } \\
56(28 \%) \\
\end{array}$} & \multirow{2}{*}{$\begin{array}{l}\text { Observe, not } \\
\text { interested in } \\
113(56.5 \%)\end{array}$} & \multirow{2}{*}{$\begin{array}{c}\text { Observe, } \\
\text { interested in } \\
31(15.5 \%)\end{array}$} & \\
\hline$I$ Vitamins and minorals & Purchace & Yes & & & & \\
\hline 1. vilamins ana minerals & r uintilase & No & $52(58.4 \%)$ & $35(39.3 \%)$ & $2(2.3 \%)$ & 89 \\
\hline \multirow{2}{*}{ II. Medicines for immune support } & \multirow{2}{*}{ Purchase } & Yes & $44(29.3 \%)$ & $83(55.3 \%)$ & $23(15.4 \%)$ & 150 \\
\hline & & No & $64(46 \%)$ & $65(46.8 \%)$ & $10(7.2 \%)$ & 139 \\
\hline \multirow{2}{*}{ III. Painkillers } & \multirow{2}{*}{ Purchase } & Yes & $80(35.1 \%)$ & $119(52.2 \%)$ & $29(12.7 \%)$ & 228 \\
\hline & & No & $28(45.9 \%)$ & $29(47.5 \%)$ & $4(6.6 \%)$ & 61 \\
\hline \multirow{2}{*}{ IV. Pharmaceutical cosmetics } & \multirow{2}{*}{ Purchase } & Yes & $44(30.1 \%)$ & $84(57.6 \%)$ & $18(12.3 \%)$ & 146 \\
\hline & & No & $64(44.8 \%)$ & $64(44.8 \%)$ & $15(10.4 \%)$ & 143 \\
\hline \multirow{2}{*}{$\begin{array}{l}V . \text { Medicines to support the } \\
\text { nervous system }\end{array}$} & \multirow{2}{*}{ Purchase } & Yes & $16(30.2 \%)$ & $27(50.9 \%)$ & $10(18.9 \%)$ & 53 \\
\hline & & No & $92(39 \%)$ & $121(51.3 \%)$ & $23(9.7 \%)$ & 236 \\
\hline \multicolumn{3}{|l|}{ Total } & $108(37.4 \%)$ & $148(51.2 \%)$ & $33(11.4 \%)$ & 289 \\
\hline
\end{tabular}


